\title{
Activation, Deficiency, and Reduced IFN- $\gamma$ Production of Mucosal-Associated Invariant T Cells in Patients with Inflammatory Bowel Disease
}

\author{
Jae Kyun Ju ${ }^{a}$ Young-Nan Cho ${ }^{b}$ Ki-Jeong Park ${ }^{b}$ Han Deok Kwak ${ }^{a}$ Hye-Mi Jin ${ }^{b}$ \\ Seon-Young Park ${ }^{c}$ Hyun Soo Kim ${ }^{c}$ Seung-Jung Kee ${ }^{d}$ Yong-Wook Park ${ }^{b}$ \\ aDepartment of Surgery, Chonnam National University Medical School and Hospital, Gwangju, Republic of Korea; \\ bepartment of Rheumatology, Chonnam National University Medical School and Hospital, Gwangju, \\ Republic of Korea; 'Department of Gastroenterology, Chonnam National University Medical School and Hospital, \\ Gwangju, Republic of Korea; dDepartment of Laboratory Medicine, Chonnam National University Medical School \\ and Hospital, Gwangju, Republic of Korea
}

\section{Keywords}

Activation $\cdot$ Inflammatory bowel disease $\cdot$ Interferon- $\gamma$ •

Mucosal-associated invariant T cells · Migration

\begin{abstract}
Mucosal-associated invariant T (MAIT) cells are innate-like T cells that can activate either in response to T-cell receptor (TCR) engagement or through activating cytokines and play an important role in autoimmune disorders. The study examined the level and function of MAIT cells in patients with inflammatory bowel disease (IBD). Circulating MAIT cell levels were significantly reduced in IBD patients. This MAIT cell deficiency was correlated with IBD disease activity grades, hemoglobin, and CRP. IFN- $\gamma$ production of circulating MAIT cells in response to both MHC class $1 \mathrm{~b}$-like related protein (MR1)-dependent and -independent stimulations was decreased in IBD patients, which was partially associated with reduced activation of nuclear factor of activated T cells 1 (NFAT1) transcription factor, a main regulator of IFN- $\gamma$ production. Expression levels of CD69, programmed death-1 (PD-1), and annexin V in MAIT cells were elevated in IBD patients. CCL20, CXCL10, CXCL16, and CCL25 were expressed higher in inflamed intestinal tissues than in noninflamed tis-
\end{abstract}

karger@karger.com www.karger.com/jin Karger"
(C) 2020 The Author(s)

Published by S. Karger AG, Basel

Karger

Open access

This article is licensed under the Creative Commons AttributionNonCommercial-NoDerivatives 4.0 International License (CC BYNC-ND) (http://www.karger.com/Services/OpenAccessLicense). Usage and distribution for commercial purposes as well as any distribution of modified material requires written permission. sues. This study demonstrates that circulating MAIT cells are activated and numerically and functionally deficient in IBD patients. Furthermore, activated MAIT cells have the potential to migrate to inflamed tissues. These findings suggest an important role of MAIT cells in mucosal immunity in IBD.

(C) 2020 The Author(s)

Published by S. Karger AG, Basel

\section{Introduction}

Inflammatory bowel diseases (IBDs), including ulcerative colitis (UC) and Crohn's disease (CD), are chronic inflammatory diseases of unknown origin. IBD has become a global disease with increasing incidence in newly industrialized and westernized countries. Genetic and environmental factors with inadequate host immune response to gut flora appear to play important roles in the pathogenesis of IBD [1-3]. Adaptive immune response has been classically considered to play a major role in IBD pathogenesis [4]. Infiltrating lymphocytes including $\mathrm{T}$

Jae Kyun Ju, Young-Nan Cho, Ki-Jeong Park, and Seung-Jung Kee contributed equally to this work. 
helper (Th) 1 cells and Th17 cells can lead to the development of intestinal lesions [5]. However, recent evidences suggest that innate immune response is equally important in inducing gut inflammation [6]. Altered epithelial barrier function and aberrant innate immune responses contribute to intestinal inflammation in IBD patients [6].

Mucosal-associated invariant T (MAIT) cells are innate lymphocytes that express a conserved invariant $\mathrm{T}$ cell receptor (TCR) Va7.2-Ja33 chain paired with a limited set of V $\beta$ chains [7]. Using distinct pairs of TCR chains, MAIT cells can recognize bacteria-derived riboflavin (vitamin B2) metabolites presented by MHC class 1b-like related protein (MR1) [7, 8]. Upon MR1-dependent recognition of antigens, MAIT cells are activated to rapidly release Th1/Th17 proinflammatory cytokines (i.e., interferon [IFN]- $\gamma$, tumor necrosis factor [TNF]- $\alpha$, and interleukin [IL]-17) and cytotoxic molecules (i.e., granzyme and perforin) to kill infected host cells [9]. MAIT cells are abundant in peripheral blood where they express gut-homing chemokine receptors such as CCR6 and CCR9. They are also abundant in intestinal mucosa where they likely confront normal flora or pathogenic bacteria producing bacterial ligands $[10,11]$. Given tissue-homing properties and rapid production of proinflammatory cytokines, MAIT cells may play an important role in infectious diseases [12-18] and autoimmune disorders [19-21].

Results from experiment with transfer of MAIT cells to TNBS-induced IBD murine models suggest that MAIT cells might play a protective role in TNBS-induced intestinal inflammation [22]. In addition, previous studies have reported MAIT cell dysfunction in IBD patients [21, $23,24]$. However, the role of MAIT cells in IBD patients remains unclear. Accordingly, the objectives of this study were (1) to examine the level and function of MAIT cells in IBD patients, (2) to evaluate the clinical relevance of MAIT cell levels, and (3) to determine the mechanism responsible for MAIT cell dysfunction.

\section{Patients and Methods}

\section{Subjects}

The study cohort included 40 patients with IBD (12 women and 28 men, mean age \pm SD: $33.2 \pm 14.6$ years) and 30 healthy controls (HCs; 14 women and 16 men, mean age \pm SD: $31.5 \pm 13.7$ years). IBD patients consisted of $22 \mathrm{CD}$ patients and $18 \mathrm{UC}$ patients. The cohort had no history of respiratory disorders such as chronic obstructive pulmonary disease or pulmonary embolism, autoimmune diseases, infectious diseases, recent surgery, malignancies, left ventricular dysfunction, use of immunosuppressive drugs, or chronic liver, renal, and endocrine diseases. Clinical and labora-
Table 1. Clinical and laboratory characteristics of 40 patients with IBD

\begin{tabular}{lc}
\hline Characteristic & IBD \\
\hline Total (CD/UC), $n$ & $40(22 / 18)$ \\
Sex, male/female, $n$ & $28 / 12$ \\
Age (mean \pm SD), years & $33.2 \pm 14.6$ \\
Disease activity & \\
Grade 1 (remission) & 17 \\
Grade 2 (mild) & 15 \\
Grade 3 (moderate) & 4 \\
Grade 4 (severe) & 1 \\
NA & 3 \\
Medication & \\
5-ASA, $n$ (\%) & $36(90)$ \\
Azathioprine, $n(\%)$ & $16(40)$ \\
Laboratory variables $(\mathrm{mean} \pm \mathrm{SD})$ & \\
Leukocyte count, cells/ $\mu \mathrm{L}$ & $6,903 \pm 2,370$ \\
Lymphocyte count, cells/ $\mu \mathrm{L}$ & $1,642 \pm 906.1$ \\
Hemoglobin level, g/dL & $12.7 \pm 2.38$ \\
Neutrophil count, cells/ $\mu \mathrm{L}$ & $14,251 \pm 21,933$ \\
Platelet count, $\times 10^{3}$ cells/ $\mu \mathrm{L}$ & $283.4 \pm 120.6$ \\
Total protein level, g/dL & $5.93 \pm 7.946$ \\
Albumin, g/dL & $5.03 \pm 1.50$ \\
Creatinine, mg/dL & $4.12 \pm 13.96$ \\
CRP level, mg/dL & $2.61 \pm 4.00$ \\
ESR level, mm/h & $35.6 \pm 22.31$ \\
& \\
&
\end{tabular}

IBD, inflammatory bowel disease; CD, Crohn's disease; UC, ulcerative colitis; NA, not available; 5-ASA, 5-acetylsalicylic acid; CRP, C-reactive protein; ESR, erythrocyte sedimentation rate. a Disease activity of Crohn's disease and ulcerative colitis was based on Crohn's Disease Activity Index (CDAI) and Mayo Clinical Index (MCI) for Assessment of Ulcerative Colitis Activity, respectively: grade 1 , remission (CDAI $<150, \mathrm{MCI} \leq 2$ ); grade 2 , mild $(150 \leq \mathrm{CDAI} \leq 220,3 \leq \mathrm{MCI} \leq 5)$; grade 3 , moderate $(220<\mathrm{CDAI} \leq$ $450,6 \leq \mathrm{MCI}<10)$; and grade 4 , severe $(\mathrm{CDAI}>450, \mathrm{MCI} \geq 10)$.

tory characteristics of patients are summarized in Table 1. Based on clinical disease activity including Crohn's Disease Activity Index (CDAI) and Mayo Clinical Index (MCI) for Assessment of Ulcerative Colitis Activity [25-27], 40 patients with IBD were classified into the following 4 grades: grade 1 , remission $(\mathrm{CDAI}<150$, $\mathrm{MCI} \leq 2)$; grade 2 , mild $(150 \leq \mathrm{CDAI} \leq 220,3 \leq \mathrm{MCI} \leq 5)$; grade 3 , moderate $(220<\mathrm{CDAI} \leq 450,6 \leq \mathrm{MCI}<10)$; and grade 4 , severe $(\mathrm{CDAI}>450, \mathrm{MCI} \geq 10)$. Of these 40 IBD patients, 17 patients had IBD of remission state, 15 patients had mild IBD, 4 patients had moderate IBD, 1 patient had severe IBD, and the remaining 3 patients were not available for classification.

\section{Monoclonal Antibodies and Flow Cytometry}

The following monoclonal antibodies (mAbs) and reagents were used in this study: allophycocyanin (APC)-Cy7-conjugated anti-CD3, phycoerythrin (PE)-Cy5-conjugated anti-CD161, fluorescein isothiocyanate (FITC)-conjugated anti-TCR $\gamma \delta$, FITCconjugated anti-CD3, FITC-conjugated anti-IFN- $\gamma$, PE-conjugated anti-IL-17, PE-Cy7-conjugated anti-TNF- $\alpha$, PE-conjugated 
anti-CD69, PE-conjugated anti-lymphocyte-activation gene3 (LAG3), FITC-conjugated mouse IgG isotype, PE-conjugated mouse IgG isotype, and PE-Cy7-conjugated mouse IgG isotype control (all from Becton Dickinson, San Diego, CA, USA); PEconjugated anti-programmed cell death-1 (PD-1; eBioscience, San Diego, CA, USA) and APC-conjugated anti-TCR Va7.2 (BioLegend, San Diego, CA, USA). Cells were stained with combinations of appropriate $\mathrm{mAbs}$ for $20 \mathrm{~min}$ at $4^{\circ} \mathrm{C}$. Stained cells were analyzed on a Navios flow cytometer using Kaluza software (Beckman Coulter, Brea, CA, USA).

\section{Isolation of Peripheral Blood Mononuclear Cells and}

Identification of MAIT Cells.

Peripheral venous blood samples were collected in heparincontaining tubes and peripheral blood mononuclear cells (PBMCs) were isolated by density-gradient centrifugation using FicollPaque Plus solution (Amersham Bioscience, Uppsala, Sweden). MAIT cells were identified phenotypically as CD3+TCR $\gamma \delta-$ $\mathrm{V} \alpha 7.2+\mathrm{CD} 161^{\text {high }}$ by flow cytometry as previously described [10, 20,28 . Total lymphocyte numbers were measured with a Coulter LH750 automatic hematology analyzer (Beckman Coulter, Miami, FL, USA). Absolute numbers of MAIT cells were calculated by multiplying MAIT cell percentages by $\mathrm{CD} 3+\gamma \delta-\mathrm{T}$-cell percentages and total lymphocyte numbers (per microliter) in peripheral blood.

\section{Functional MAIT Cell Assay}

Expression levels of IFN- $\gamma$, IL-17A, and TNF- $\alpha$ in MAIT cells were detected by intracellular cytokine flow cytometry as previously described $[10,11,19,28]$. In brief, freshly isolated PBMCs $\left(1 \times 10^{6} /\right.$ well $)$ were incubated in $1 \mathrm{~mL}$ complete media consisting of RPMI 1640, 2 mM L-glutamine, 100 units/mL of penicillin, and $100 \mu \mathrm{g} / \mathrm{mL}$ of streptomycin and supplemented with $10 \%$ fetal bovine serum (FBS; Gibco BRL, Grand Island, NY, USA) with or without ERK inhibitor (PD98059, $50 \mu \mathrm{M}$; Calbiochem, San Diego, CA, USA) for $1 \mathrm{~h}$, p38 MAPK inhibitor (SB220025, $10 \mu \mathrm{M}$; Calbiochem) for $1 \mathrm{~h}$, or calcineurin inhibitor (cyclosporin A [CsA], $2 \mu \mathrm{M}$; Calbiochem) for $30 \mathrm{~min}$. They were then stimulated with PMA (100 $\mathrm{ng} / \mathrm{mL}$; Sigma, St. Louis, MO, USA) and ionomycin (IM; $1 \mu \mathrm{M}$; Sig$\mathrm{ma}$ ) for $4 \mathrm{~h}$. For intracellular cytokine staining, $1 \mu \mathrm{L}$ brefeldin A (GolgiPlug; BD Biosciences, San Diego, CA, USA) was added. The final concentration of brefeldin A was $10 \mu \mathrm{g} / \mathrm{mL}$. After incubation for an additional $4 \mathrm{~h}$, the cells were stained with APC-Alexa Fluor 750-conjugated anti-CD3, PE-Cy5-conjugated anti-CD161, and APC-conjugated anti-TCR Va7.2 $\mathrm{mAb}$ for $20 \mathrm{~min}$ at $4^{\circ} \mathrm{C}$, fixed with $4 \%$ paraformaldehyde for $15 \mathrm{~min}$ at room temperature, and permeabilized with Perm/Wash solution (BD Biosciences) for 10 min. Cell were then stained with FITC-conjugated anti-IFN- $\gamma$, PEconjugated anti-IL-17A, or PE-Cy7-conjugated anti-TNF- $\alpha$ mAbs for $30 \mathrm{~min}$ at $4^{\circ} \mathrm{C}$ and analyzed by flow cytometry.

\section{In vitro Infection with Escherichia coli}

In vitro infection was performed as previously described [10, 29]. E. coli was provided by Clinical Microbiology Laboratory of Chonnam National University Hospital. American Type Culture Collection E. coli 25922 reference strain was used. E. coli cells were opsonized for 2 min using the RPMI1640 medium (Life Technologies BRL) supplemented with $2 \%$ human serum and 10\% FBS. They were then washed twice in a complete medium without antibiotics. Opsonized E. coli were passed through a $5-\mu \mathrm{m}$ syringe filter (Millipore, Billerica, MA, USA), counted in a Petroff-Hausser chamber, and added to THP-1 cells (American Type Culture Collection) at a multiplicity of infection of 10 . The duration of infection was $2 \mathrm{~h}$ for all experiments. Infected THP- 1 cells $\left(1 \times 10^{6} \%\right.$ well) used as APCs were washed twice with the RPMI 1640 medium without antibiotics and then cultured with freshly isolated PBMCs $\left(1 \times 10^{6} /\right.$ well $)$ for $24 \mathrm{~h}$. Production of IFN- $\gamma$, IL-17A, and TNF- $\alpha$ by MAIT cells was determined by intracellular cytokine flow cytometry.

\section{Western Blot Analysis}

Western blotting was performed as previously described [30, 31 ]. In brief, purified MAIT cells $\left(1 \times 10^{6}\right.$ cells/well $)$ were stimulated with IM $(1 \mu \mathrm{M})$ for $3 \mathrm{~min}$, harvested after washing with icecold phosphate-buffered saline (PBS), and lysed in the extraction buffer consisting of $50 \mathrm{~mm}$ Tris- $\mathrm{HCl}$ (pH8.0), $150 \mathrm{~mm} \mathrm{NaCl}, 2 \mathrm{~mm}$ EDTA, $1 \%$ Triton X-100, 0.1\% sodium dodecyl sulfate (SDS), $1 \%$ sodium deoxycholate, and $0.01 \%$ protease inhibitor mixture. Proteins $(5 \mu \mathrm{g})$ were resolved by $10 \%$ SDS-PAGE (sodium dodecyl sulfate-polyacrylamide gel electrophoresis) and then transferred to polyvinylidene difluoride (PVDF) membranes (Amersham Biosciences, Piscataway, NJ, USA). The membranes were treated with $5 \%$ skim milk for $1 \mathrm{~h}$ and incubated with a series of antibodies, including nuclear factor of activated T cells 1 (NFAT1; BD Biosciences) and actin (Sigma, St. Louis, MO, USA). They were then incubated with horseradish peroxidase (HRP)-conjugated secondary antibodies (Abcam, Cambridge, UK). Blots were developed with enhanced chemiluminescence (ECL) solution (Millipore Corporation, Billerica, MA, USA). Signals were detected and analyzed using a LAS3000 luminescent image analyzer (Fuji Photo Film, Tokyo, Japan). NFAT1 levels were represented by the ratios of dephospho-(active form) NFAT1 to phospho-(inactive form) NFAT1. The NFAT1/pNFAT1 ratios were normalized to the levels of actin.

\section{Statistical Analysis}

All comparisons of percentages, absolute numbers, cytokine levels and ratios of MAIT cells, and expression levels of CD69, PD1 , and LAG3 were performed by analysis of covariance after adjusting for age and sex using Bonferroni correction for multiple comparisons. Changes in IFN- $\gamma$ levels in MAIT cells after treatment with PMA and IM with or without inhibitors of the signaling pathway were examined using a paired $t$ test. Linear regression analysis was used to test associations between MAIT cell levels and clinical or laboratory parameters. Comparisons of NFAT1/pNFAT1 ratios between HCs and IBD patients were performed by the MannWhitney $U$ test. Statistical significance was considered when $p$ value $<0.05$. All statistical analyses were performed using SPSS version 18.0 software (SPSS Inc., Chicago, IL, USA).

\section{Results}

\section{Reduced Numbers of Circulating MAIT Cells in IBD Patients}

Percentages and absolute numbers of MAIT cells in peripheral blood samples of 22 patients with CD, 18 patients with UC, and $30 \mathrm{HCs}$ were determined by flow cy- 

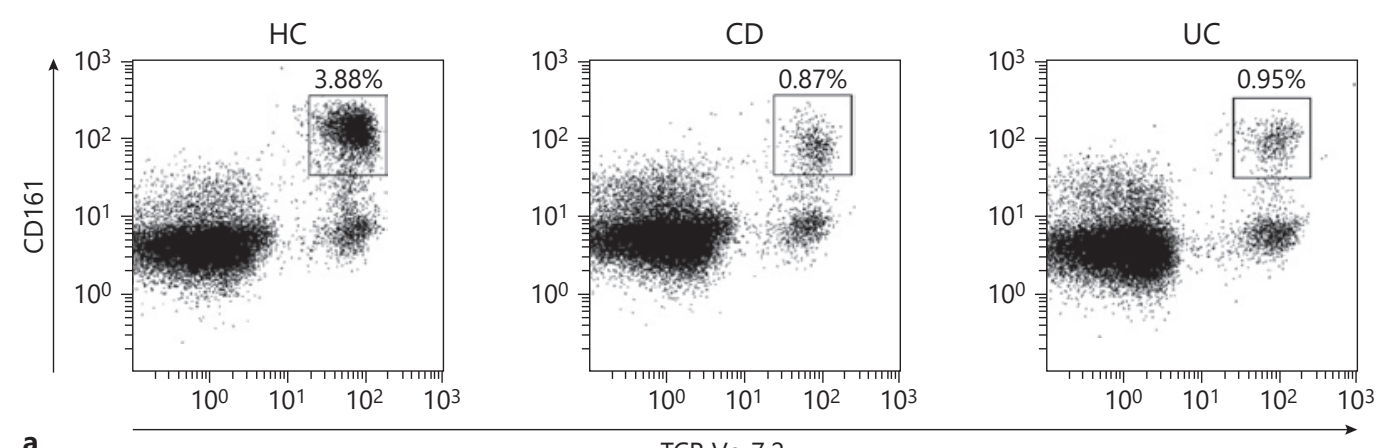

a

TCR $V \propto \alpha .2$
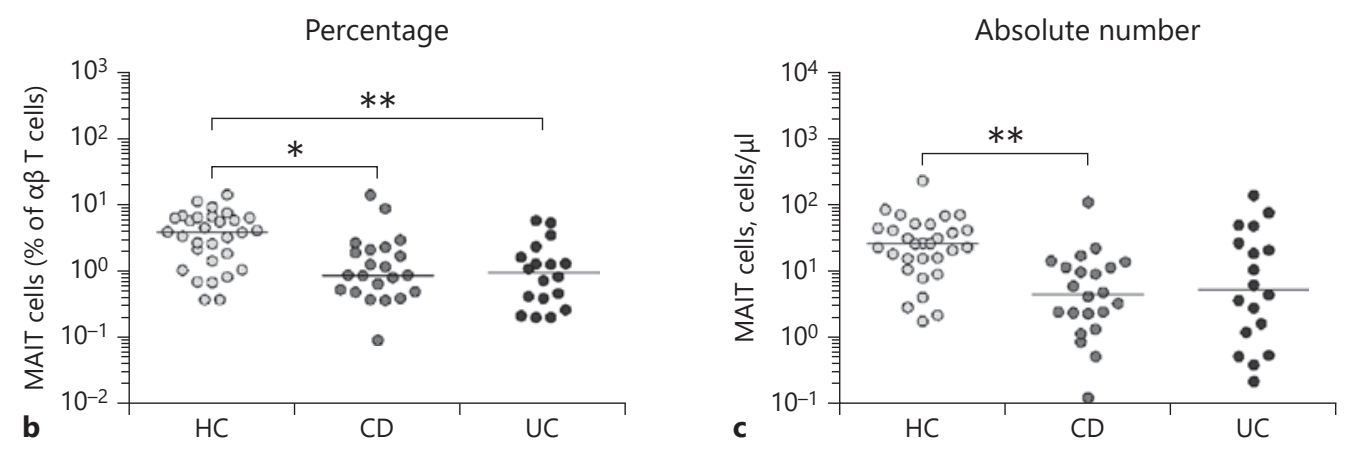

Fig. 1. Decreased circulating MAIT cell proportions in peripheral blood of IBD patients. Freshly isolated PBMCs from $30 \mathrm{HCs}, 22$ patients with $\mathrm{CD}$, and 18 patients with UC were stained with APCCy7-conjugated anti-CD3, FITC-conjugated anti-TCR $\gamma \delta$, APCconjugated anti-TCR Va7.2, and PE-Cy5-conjugated anti-CD161 $\mathrm{mAbs}$ and then analyzed by flow cytometry. Percentages of MAIT cells were calculated within a $\alpha \beta$ T-cell gate. a Representative MAIT cell percentages as determined by flow cytometry. b MAIT

tometry. All comparisons of percentages and absolute numbers of MAIT cells were performed by analysis of covariance after adjusting for age and sex using Bonferroni correction for multiple comparisons as described in the section Patients and Methods. MAIT cells were defined as $\mathrm{CD} 3+\gamma \delta-\mathrm{T}$ cells expressing TCR Va7.2 and CD$161^{\text {high }}$ (Fig. 1a). Percentages of MAIT cells were significantly lower in both CD and UC patients than in HCs (median 0.87 vs. $3.88 \%, p<0.05$, and 0.95 vs. $3.88 \%, p<$ 0.005 , respectively; Fig. 1b). Absolute numbers of MAIT cells were calculated by multiplying MAIT cell percentages by $\mathrm{CD} 3+\mathrm{TCR} \gamma \delta-\mathrm{T}$-cell percentages and total lymphocyte numbers (per microliter of peripheral blood). CD patients had significantly lower absolute numbers of MAIT cells than HCs (median 4.74 vs. 27.3 cells $/ \mu \mathrm{L}, p<$ 0.005). However, the absolute numbers of MAIT cells cell percentages among peripheral blood $\alpha \beta \mathrm{T}$ cells. c Absolute MAIT cell numbers (per microliter of blood). Symbols represent individual subjects. Horizontal lines are median values. MAIT, mucosal-associated invariant T; IBD, inflammatory bowel disease; PBMC, peripheral blood mononuclear cell; HC, healthy control; $\mathrm{CD}$, Crohn's disease; UC, ulcerative colitis; APC, allophycocyanin; FITC, fluorescein isothiocyanate; TCR, T-cell receptor; PE, phycoerythrin. ${ }^{*} p<0.05,{ }^{* *} p<0.005$ by the ANCOVA test. 
Table 2. Regression coefficients for log-transformed absolute MAIT cell numbers with respect to clinical and laboratory findings in patients with IBD

\begin{tabular}{lcll}
\hline Variables & $\beta^{\mathrm{a}}$ & $\mathrm{SE}$ & $p$ value \\
\hline Sex & -0.054 & 0.254 & 0.832 \\
Age, years & 0.004 & 0.008 & 0.580 \\
IBD activity grade ${ }^{\mathrm{b}}$ & -0.342 & 0.148 & $0.027^{*}$ \\
Leukocyte count, cells/ $\mu \mathrm{L}$ & -0.0001 & 0.000 & 0.287 \\
Lymphocyte count, cells/ $\mu \mathrm{L}$ & 0.000 & 0.000 & 0.103 \\
Monocyte count, cells/ $\mu \mathrm{L}$ & 0.000 & 0.001 & 0.496 \\
Neutrophil count, cells $\mu \mathrm{L}$ & -0.0001 & 0.000 & 0.703 \\
Hemoglobin, g/dL & 0.164 & 0.042 & $0.000^{*}$ \\
Platelet count, $\times 10^{3}$ cells/ $\mu \mathrm{L}$ & -0.002 & 0.001 & 0.070 \\
Creatinine, mg/dL & 0.003 & 0.009 & 0.750 \\
Total protein, g/dL & 0.003 & 0.018 & 0.849 \\
Albumin, g/dL & -0.082 & 0.077 & 0.298 \\
CRP, mg/dL & -0.062 & 0.028 & $0.033^{*}$ \\
ESR, mm/h & -0.007 & 0.007 & 0.347 \\
\hline
\end{tabular}

IBD, inflammatory bowel disease; CRP, C-reactive protein; ESR, erythrocyte sedimentation rate; SE, standard error. ${ }^{\text {a }}$ Regression coefficient. ${ }^{\mathrm{b}}$ Disease activity of Crohn's disease and ulcerative colitis was based on Crohn's Disease Activity Index (CDAI) and Mayo Clinical Index (MCI) for Assessment of Ulcerative Colitis Activity, respectively: grade 1 , remission (CDAI $<150$, MCI $\leq 2$ ); grade 2 , mild $(150 \leq \mathrm{CDAI} \leq 220,3 \leq \mathrm{MCI} \leq 5)$; grade 3 , moderate $(220<\mathrm{CDAI} \leq 450,6 \leq \mathrm{MCI}<10)$; and grade 4 , severe $(\mathrm{CDAI}>450$, $\mathrm{MCI} \geq 10)$. ${ }^{*}$ Statistical significance.

log-transformed MAIT cells showed no significant correlation with sex, age, leukocyte count, lymphocyte count, monocyte count, neutrophil count, platelet count, creatinine level, total protein level, albumin level, or erythrocyte sedimentation rate (Table 2).

\section{Impaired Production of IFN- $\gamma$ in Circulating MAIT}

Cells of IBD Patients

To examine MR1-independent cytokine production in MAIT cells, PBMCs from 9 IBD patients and 9 HCs were incubated with PMA and IM for $1 \mathrm{~h}$ and then expression levels of IFN- $\gamma$, IL-17, and TNF- $\alpha$ in MAIT cell population were examined at single-cell level by intracellular flow cytometry (Fig. 2a, c). Percentages of IFN- $\gamma+$ MAIT cells were found to be significantly lower in IBD patients than in HCs (median 46.9 vs. $65.4 \%, p<0.05$ ). IL- $17+$ and TNF- $\alpha+$ MAIT cell levels were comparable between IBD patients and HCs. Mean fluorescence intensities (MFIs) of IFN- $\gamma$ production by MAIT cells were also found to be significantly lower in IBD patients than in HCs (median 12.4 vs. $5.95, p<0.05)$. However, MFIs of IL-17 and TNF- $\alpha$ on MAIT cell were comparable between IBD patients and HCs (see online suppl. Fig. 1a; for all online suppl. material, see www.karger.com/doi/10.1159/000507931). Next, we examined MR1-dependent cytokine production by MAIT cells. PBMCs from 9 IBD patients and 9HCs were stimulated for $24 \mathrm{~h}$ with $E$. coli-infected THP-1 cells, and then the production of IFN- $\gamma$, IL-17, and TNF- $\alpha$ in MAIT cells was examined by intracellular cytokine flow cytometry (Fig. 2b, d). Percentages of IFN- $\gamma+$ MAIT cells were found to be significantly lower in IBD patients than in HCs (median 12.3 vs. $20.5 \%, p<0.005)$. IL-17+ and TNF- $\alpha+$ MAIT cell levels were similar between IBD patients and HCs. However, MFIs of IFN- $\gamma$, IL-17, and TNF- $\alpha$ by MAIT cells were also comparable between IBD patients and HCs (online suppl. Fig. 1b). Moreover, ratios of IL-17/IFN- $\gamma$ production in response to PMA and IM were significantly higher in IBD patients than in HCs (median ratio 0.08 vs. $0.22, p<0.01$ ). However, ratios of IL-17/IFN- $\gamma$ production in response to E. coli-infected THP-1 cells or those of TNF- $\alpha / \mathrm{IFN}-\gamma$ production in response to both stimulations were comparable between IBD patients and HCs (Fig. 2e, f).

\section{Activation of MAIT Cells in IBD Patients}

To determine whether activation-induced cell death could cause MAIT cell deficiency in IBD patients, CD69+ and annexin $\mathrm{V}+$ cell levels in circulating MAIT cells were determined by flow cytometry (Fig. 3a, c). Percentages of CD69+ and annexin V+ MAIT cells were found to be significantly higher in IBD patients than in HCs (median 39.9 vs. $6.09 \%, p<0.0001$, for CD69; median 15.8 vs. $11.9 \%, p<0.05$, for annexin V, respectively; Fig. 3b, d). To determine whether impaired IFN- $\gamma$ production by MAIT cells was related to $\mathrm{PD}-1$, a representative coinhibitory receptor implicated in T-cell anergy $[32,33]$, we examined expression levels of PD-1 in peripheral blood samples of 20 IBD patients and 15 HCs. Expression levels of PD-1 were found to be significantly higher in IBD patients than in HCs (median 27.8 vs. $3.73 \%, p<0.0001$; Fig. 3e, f).

\section{Expression Levels of Chemokines in IBD Tissues}

To determine whether MAIT cells might have the capability of trafficking into peripheral target tissues (i.e., intestine), the pattern of tissue-homing chemokine receptor expression in circulating MAIT cells was determined by flow cytometry. MAIT cells in peripheral blood exhibited high levels of CCR6 and CXCR6, intermediate levels of CXCR3, and low levels of CCR9. These chemokine receptor expressions were comparable between IBD patients and HCs (Fig. 4a, b). We also analyzed the pattern of each corresponding chemokine expression in paired samples of inflamed and its adjacent noninflamed 


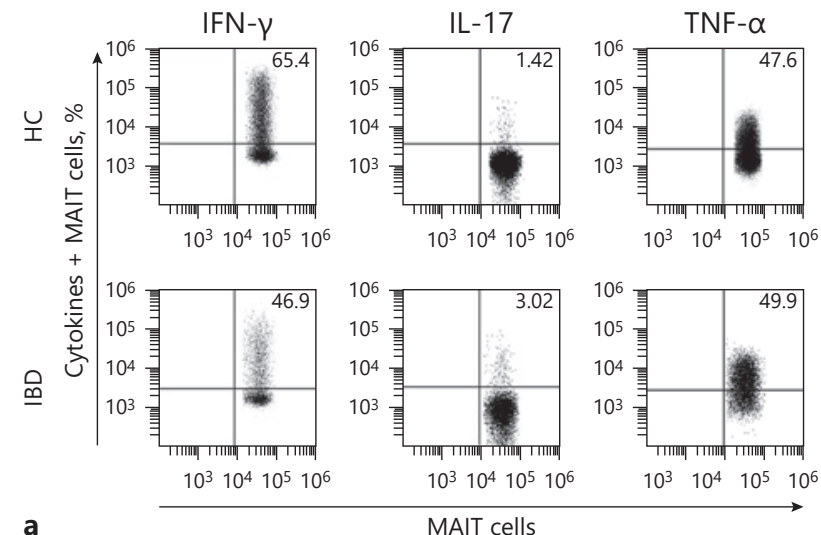

$\mathrm{PMA}+$ ionomycin
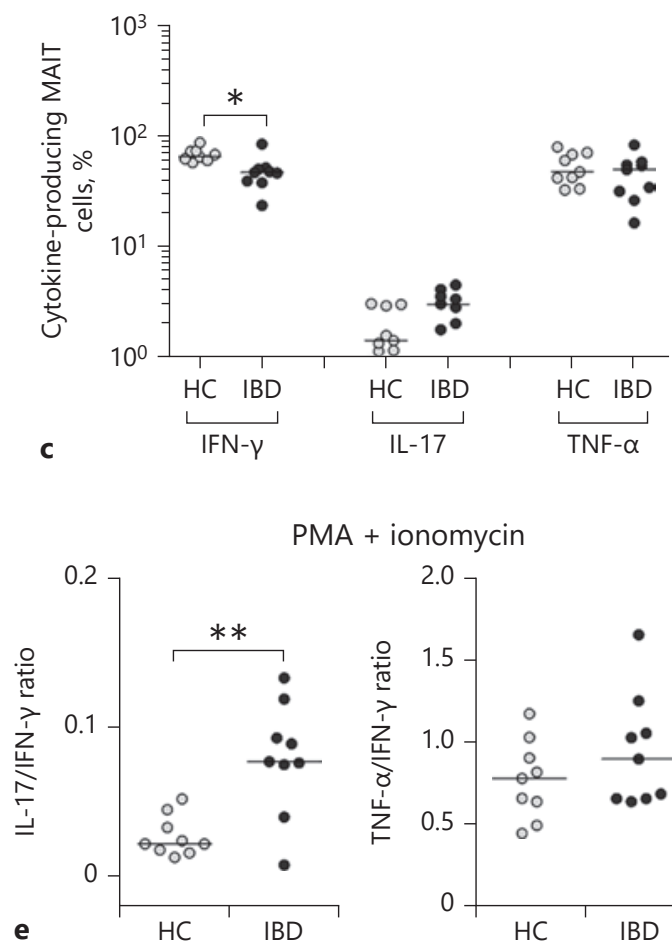

$\mathrm{MA}+$ ionomycin

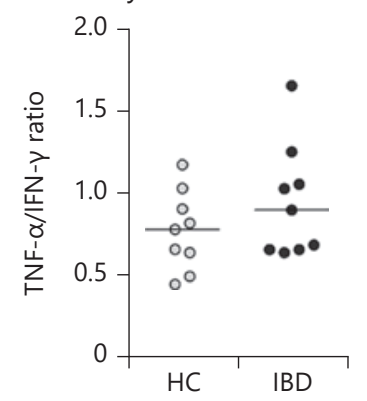

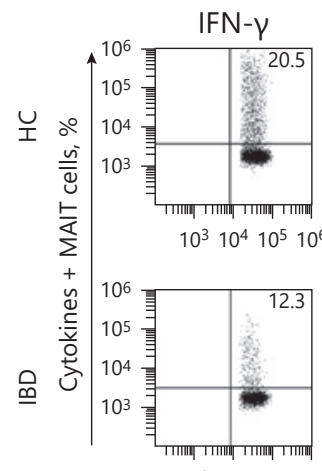
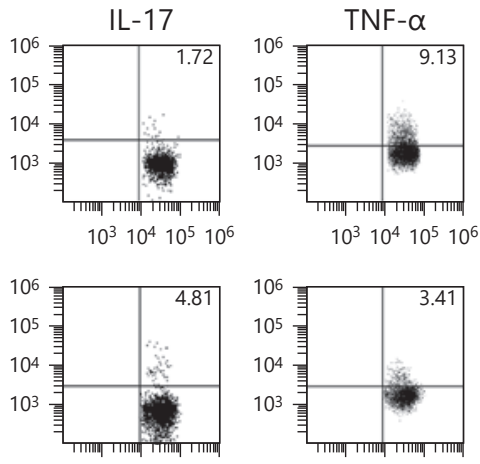

b

MAIT cells

E. coli-infected APC

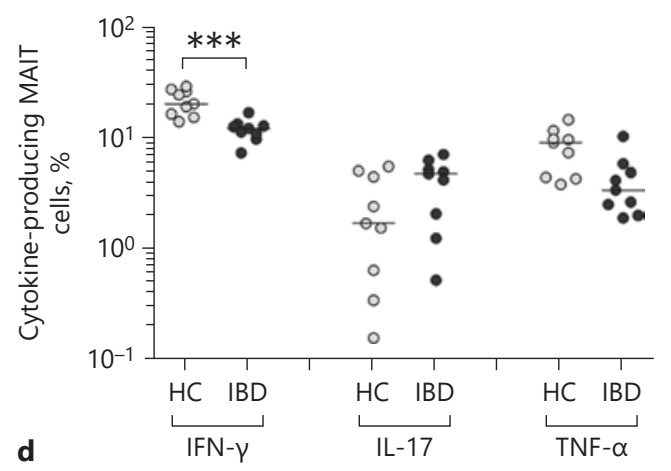

E. coli-infected APC

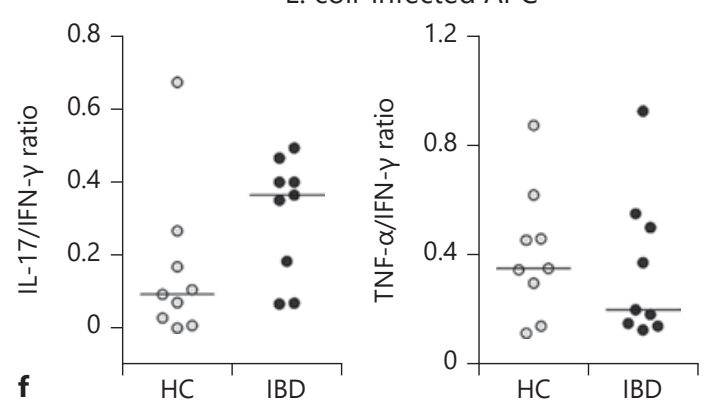

Fig. 2. Reduced expression of IFN- $\gamma$ in circulating MAIT cells of IBD patients. Freshly isolated PBMCs $\left(1 \times 10^{6} /\right.$ well $)$ were incubated with PMA $(100 \mathrm{ng} / \mathrm{mL})$ and IM $(1 \mu \mathrm{M})$ for $1 \mathrm{~h}$ or with $E$. coli-infected THP-1 cells $\left(1 \times 10^{6} /\right.$ well $)$ for $24 \mathrm{~h}$. Representative IFN- $\gamma$, IL-17, and TNF- $\alpha$ expression levels in MAIT cell population were determined by intracellular flow cytometry after stimulation with PMA and IM (a) or with E. coli-infected THP-1 cells (b). c, d Production of cytokines in circulating MAIT cells. Data on each cytokine were obtained from 9 HCs to 9 IBD patients in response to PMA and IM (c) or E. coli-infected THP-1 cells (d). e, f Ratios of IL-17/IFN- $\gamma$ and TNF- $\alpha /$ IFN- $\gamma$ in circulating MAIT cells. Data were also obtained from 9 HCs to 9 IBD patients in response to PMA and IM (e) or with E. coli-infected THP-1 cells (f). Symbols represent individual subjects. Horizontal lines are median values. IFN, interferon; MAIT, mucosal-associated invariant T; IBD, inflammatory bowel disease; PBMC, peripheral blood mononuclear cell; IL, interleukin; HC, healthy control; APC, allophycocyanin. ${ }^{*} p<0.05,{ }^{* *} p<0.01,{ }^{* * *} p<0.005$ by the ANCOVA test. 

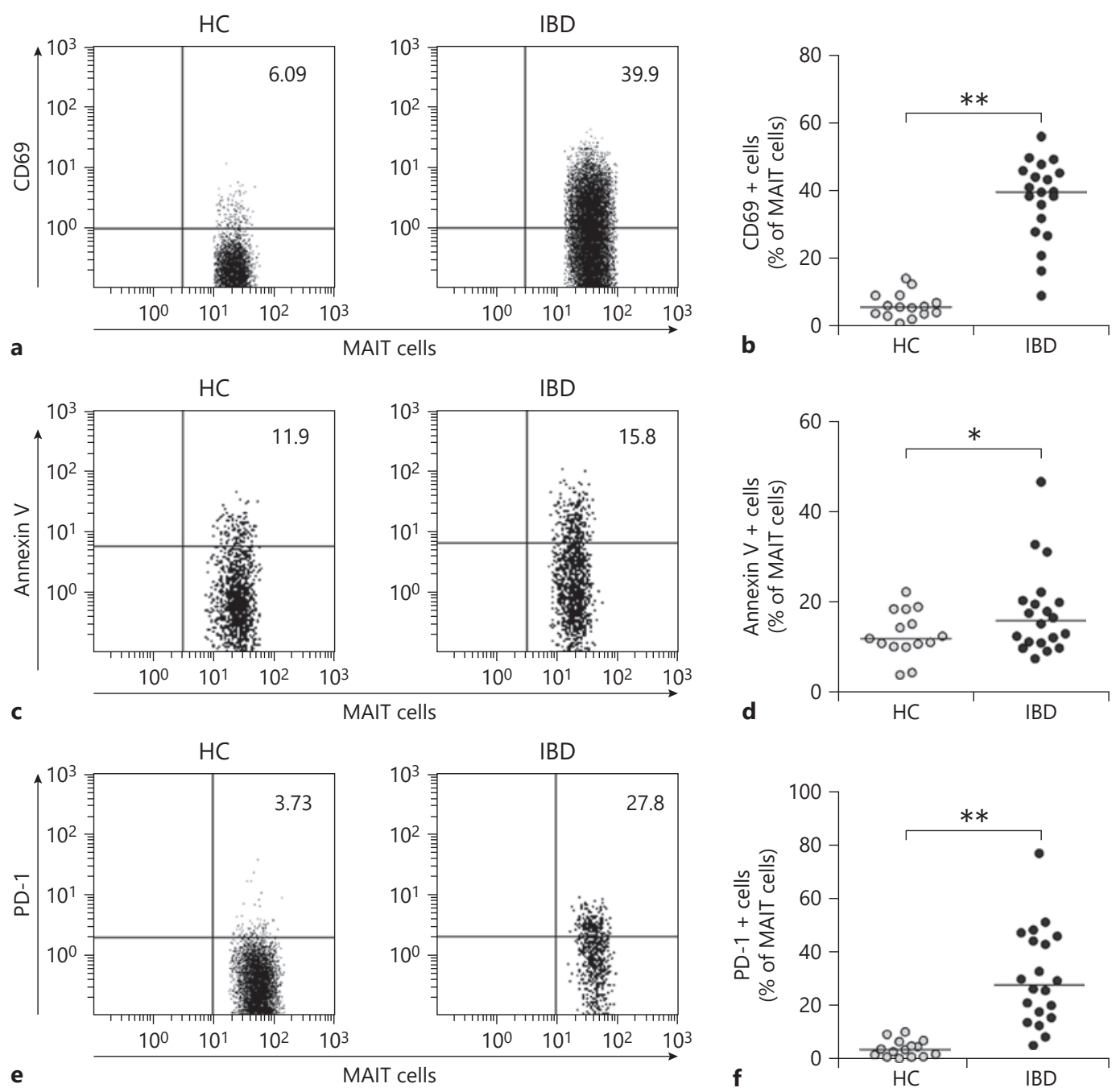

Fig. 3. Expression of CD69 and PD-1 and apoptosis in MAIT cells of IBD patients. Freshly isolated PBMCs were stained with FITCconjugated anti-CD3, FITC-conjugated annexin V, APC-conjugated anti-TCR Va7.2, PE-conjugated anti-CD3, PE-conjugated anti-CD69, PE-conjugated anti-PD-1, and PE-Cy5-conjugated anti-CD161 monoclonal antibodies and then analyzed by flow cytometry. Representative percentages of CD69-expressing cells (a), annexin $\mathrm{V}$-positive cells (c), and PD-1-expressing cells (e) among

IBD tissues by real-time PCR. All chemokine mRNAs were found to be more strongly expressed in inflamed tissues than in noninflamed tissues (Fig. 4c). Taken together, these data indicate that circulating MAIT cells have tissue tropism and that they can migrate from peripheral blood into inflamed tissue via this chemokine-chemokine receptor axis in IBD patients.
MAIT cell population. Data in $\mathbf{b}, \mathbf{d}$, and $\mathbf{f}$ were obtained from 15 HCs to 20 patients with IBD. Symbols represent individual subjects. Horizontal lines are median values. MAIT, mucosal-associated invariant $\mathrm{T}$; IBD, inflammatory bowel disease; $\mathrm{PBMC}$, peripheral blood mononuclear cell; FITC, fluorescein isothiocyanate; APC, allophycocyanin; PE, phycoerythrin; HC, healthy control. ${ }^{*} p<0.05,{ }^{* *} p<0.0001$ by the ANCOVA test.

\section{Defect in Activation of NFAT1 in MAIT Cells of IBD}

\section{Patients}

Our data showed that IFN- $\gamma$ production by MAIT cells was defective in IBD patients. To determine which the signaling pathway was the main regulator of IFN- $\gamma$ in MAIT cells, ERK (PD98059), p38 MAPK (SB220025), or calcineurin (cyclosporin A) inhibitors were added to cells 


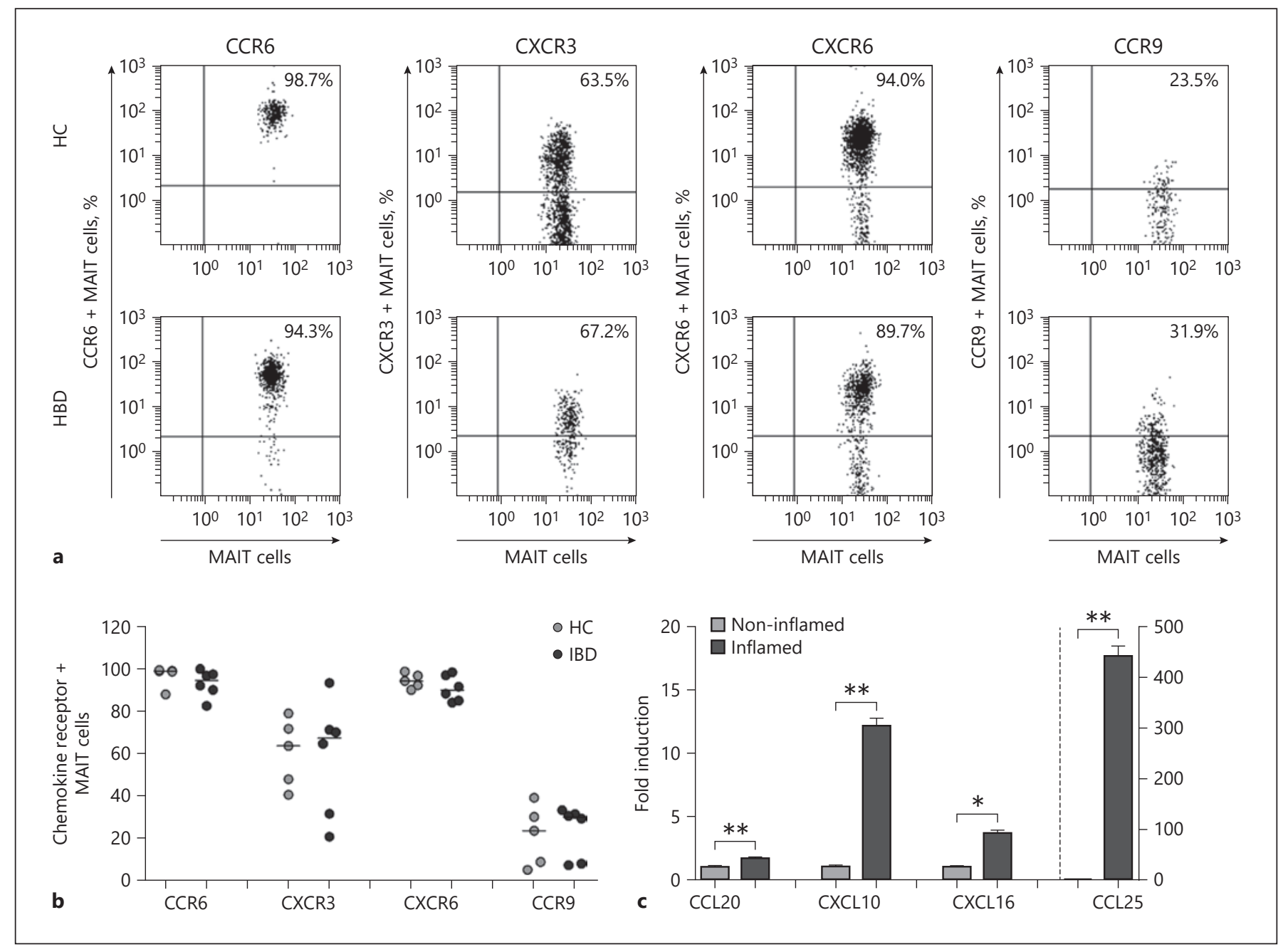

Fig. 4. Expression levels of chemokines in IBD tissues. a, b Expression of tissue-homing chemokine receptors in circulating MAIT cells. Representative staining for chemokine receptors on peripheral blood MAIT cells was analyzed by flow cytometry (a). Data in b were obtained from 6 patients with IBD and 5 HCs. c Expression

before PMA and IM stimulation. Pretreatment with cyclosporin A or PD98059 significantly reduced IFN- $\gamma$ production by MAIT cells in IBD patients. Moreover, cyclosporin A had more suppressive effect than PD98059. However, no suppressive effect of SB220025 was found in HCs and IBD patients (Fig. 5a). In addition, pretreatment with cyclosporin A significantly reduced IFN- $\gamma$ production by $\mathrm{CD} 3+\mathrm{T}$ cells in IBD patients (online suppl. Fig. 2). These findings suggest that the calcineurin-NFAT signaling pathway is the major regulator of IFN- $\gamma$ production by T cells, including MAIT cells. Thus, we analyzed activation of NFAT1 signaling from pNFAT1 (inactive form) to NFAT1 (active form) in MAIT cells by immu- levels of chemokine mRNAs in inflamed and noninflamed IBD tissues by real-time PCR. Data in c were obtained from 3 patients with IBD. Values are expressed as mean \pm SEM. MAIT, mucosalassociated invariant T; IBD, inflammatory bowel disease; HC, healthy control. ${ }^{*} p<0.05,{ }^{*} p<0.005$ by the paired $t$ test. 
Fig. 5. Defect in NFAT1 activation in MAIT cells of IBD patients. a Production of IFN- $\gamma$ in MAIT cells pretreated with each inhibitor. Freshly isolated PBMCs $\left(1 \times 10^{6} /\right.$ well $)$ were incubated PMA $(100$ $\mathrm{ng} / \mathrm{mL})$ and IM $(1 \mu \mathrm{M})$ for $4 \mathrm{~h}$ with or without inhibitors of ERK (PD98059), p38 MAPK (SB220025), or calcineurin (cyclosporin A, CsA) as described in the section Patients and Methods (a). Data in a were obtained from $5 \mathrm{HCs}$ and $5 \mathrm{IBD}$ patients. Values are expressed as mean \pm SEM. ${ }^{* *} p<$ $0.005,{ }^{* * *} p<0.001$ by paired $t$ test. $\mathbf{b}$ Western blot analysis of phospho-(inactive) and dephospho-(active) NFAT1 expression. MAIT cells were isolated from PBMCs of HCs $(n=20)$ and IBD patients $(n=20)$ by FACS sorting. Purified MAIT cells $\left(1 \times 10^{6}\right.$ cells/well) were incubated with IM $(1 \mu \mathrm{M})$ for $3 \mathrm{~min}$ and analyzed by immunoblotting with anti-NFAT1 antibody. Data in c were 3 independent experiments. Values are expressed as mean \pm SEM. NFAT1, nuclear factor of activated T cells 1; MAIT, mucosal-associated invariant T; IBD, inflammatory bowel disease; IFN, interferon; PBMC, peripheral blood mononuclear cell; HC, healthy control. ${ }^{*} p<0.05$ by the MannWhitney $U$ test.

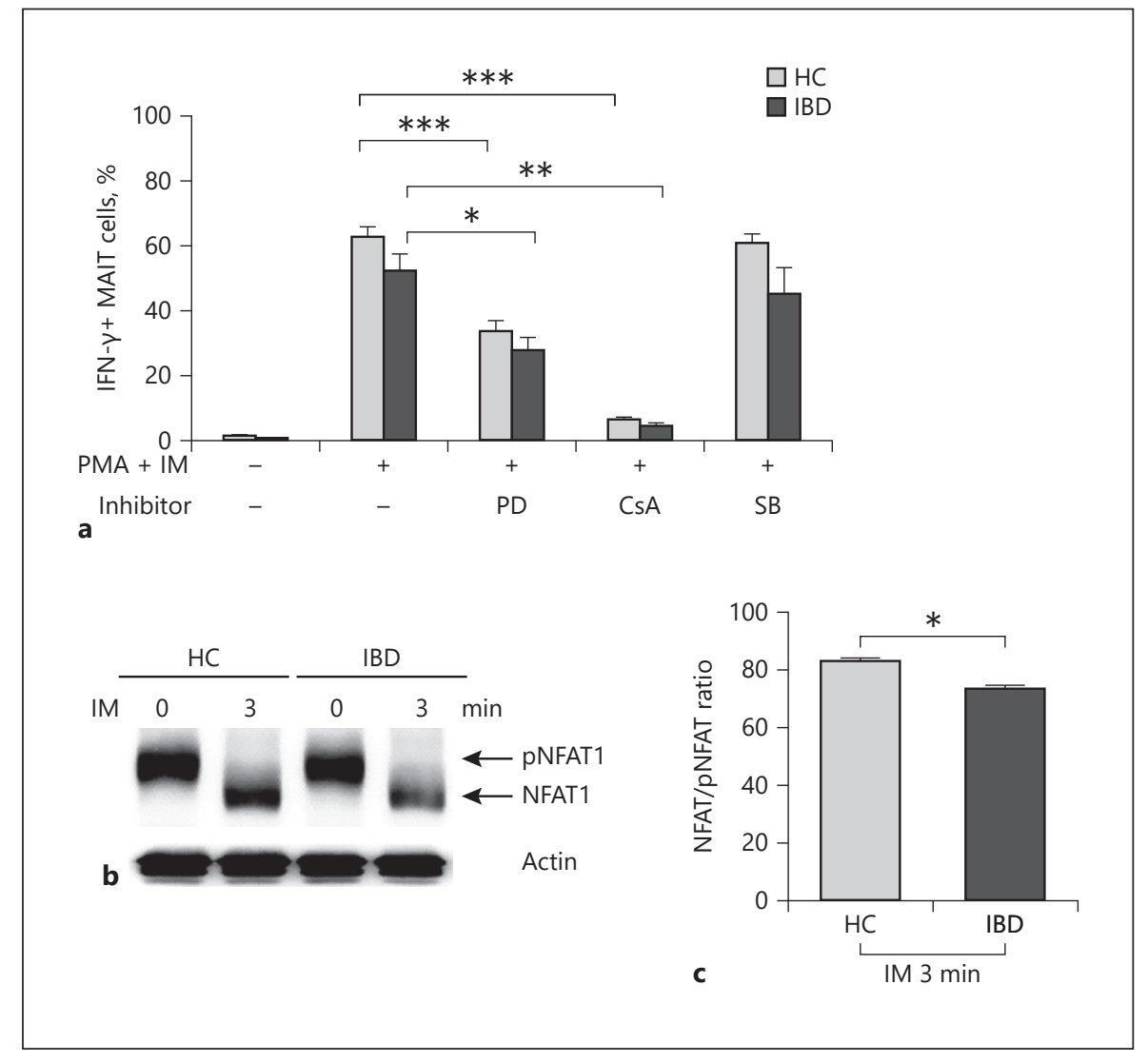

cell deficiency was correlated with IBD disease activity grades, hemoglobin, and CRP. We also observed that the numbers of CD69+, annexin $\mathrm{V}+$, and $\mathrm{PD}-1+$ in circulating MAIT cells were significantly increased in IBD patients compared with those in HCs. In addition, our study showed that the number of circulating IFN- $\gamma+$ MAIT cells in response to both MR1-dependent and -independent stimulations was decreased in IBD patients, which was partially associated with reduced activation of NFAT1 transcription factor, a main regulator of IFN- $\gamma$ production by MAIT cells. As compared with the noninflamed tissues in IBD patients, the inflamed intestinal tissues displayed the highest expression of chemokine CCL25, which is the ligand for CCR9, a gut-specific chemokine receptor. This leads us to speculate that MAIT cells might have the potential to migrate into inflamed intestine, possibly resulting in MAIT cell decrease in the peripheral blood of IBD patients.

Our data showed that the number of circulating MAIT cells was reduced in IBD patients, consistent with previous studies on IBD [21, 23, 24, 34]. Peripheral blood MAIT cell deficiency has also been reported in a variety of infectious diseases, autoimmune diseases, inflammatory diseases, and metabolic diseases $[12,13,16,18,35-$
43]. In addition, frequencies of CD3 $\mathrm{T}$ cells, $\alpha \beta \mathrm{T}$ cells, and $\gamma \delta$ T cells were found to be decreased in IBD patients compared with those in HCs (online suppl. Fig. 3). These findings suggest that decline in peripheral blood cell numbers might be a general phenomenon of $\mathrm{T}$ cells rather than specific to MAIT cells.

In the present study, circulating MAIT cell numbers were found to be inversely correlated with disease activity of IBD and CRP level. Consistent with our data, Tominaga et al. [24] have recently reported that MAIT cell numbers in peripheral blood are inversely correlated with disease activity of IBD. Furthermore, Haga et al. [34] have reported that MAIT cell frequency in inflamed mucosa is positively correlated with clinical and endoscopic disease activities in UC patients. These findings suggest that MAIT cells may migrate to inflamed mucosa, leading to peripheral blood MAIT cell deficiency. However, the enumeration of MAIT cells in the gut mucosa is lacking, which is a weakness in the present study. In addition, we clearly found a notable association between circulating MAIT cell number and hemoglobin level in IBD patients, in parallel with our previous reports on colon cancer and trauma $[41,44]$. Collectively, these findings suggest that 
circulating MAIT cell levels is associated with inflammatory or disease activity of IBD.

In the present study, fewer circulating MAIT cells from IBD patients produced IFN- $\gamma$ with increased tendency of IL-17+ MAIT cell number in response to stimulation with PMA/IM or E. coli-infected APCs, resulting in significantly increased ratio of IL-17/IFN- $\gamma$ production. When reanalyzing the data in terms of single, double, or triple cytokine producers, the impaired production of IFN- $\gamma$ in circulating MAIT cells was due to a decrease in single IFN- $\gamma$ producer, a major subset of cytokine-producing MAIT cells (online suppl. Fig. 4). In agreement with our data, Serriari et al. [21] have reported that circulating MAIT cells exhibit enhanced production of IL-17 with reduced production of IFN- $\gamma$ in $\mathrm{CD}$ patients. In addition, 2 previous studies have demonstrated that circulating MAIT cells display enhanced production of IL-17 with preserved production of IFN $-\gamma$ in IBD patients $[24,34]$. These findings suggest that circulating MAIT cells reflect a Th1-to-Th17 shift in the cytokine secretion profile in IBD patients. A clinical trial has demonstrated that ustekinumab, a human IL12/23 monoclonal antibody for targeting the Th17 pathway, is successful in treating CD patients [45]. On the contrary, data from experimental mouse colitis models have shown that administration of a neutralizing IL-17 antibody resulted in worsening of colitis [46]. Moreover, a clinical trial has shown that secukinumab, a human anti-IL-17A monoclonal antibody, was ineffective with high rates of adverse events in CD patients and that a proportion of the patients even displayed worsened disease [47]. Thus, it remains unclear whether this secretion pattern of cytokines in circulating MAIT cells plays a protective or pathological role in IBD patients.

Our data revealed that circulating MAIT cell deficiency was accompanied by upregulated expression of CD69, annexin $\mathrm{V}$, and PD-1 in circulating MAIT cells, indicating that reduction in MAIT cell numbers might be due partly to increased activation-induced cell death. Similar observations have been described in previous studies [23, 34]. In addition, we hypothesized that reduced MAIT cell number in the peripheral blood might be partly due to their migration to mucosal lesions in IBD from circulation. This hypothesis was supported by our data showing that circulating MAIT cells exhibited higher levels of CCR6 and CXCR6, intermediated level of CXCR3, and lower level of CCR9 in IBD patients, consistent with previous reports $[41,48]$. Tominaga et al. [24] have also reported that activated CCR6-expressing MAIT cells are accumulated in inflamed colon. This was further corroborated by our finding showing that inflamed colon exhibited higher expres-

MAIT Cells in Patients with IBD sions of CCL20, CXCL10, CXCL16, and CCL25 as corresponding chemokine ligands for CCR6, CXCR3, CXCR6, and CCR9, respectively, than noninflamed tissue. Taken together, these results suggest that circulating MAIT cell deficiency in IBD patients may be caused by both migration and activation-induced cell death.

In addition, we analyzed the correlation between expression of $\mathrm{PD}-1$ or chemokine receptors and cytokines produced by the MAIT cells in IBD patients. The analysis showed a moderate inverse correlation between PD-1 expression and IFN- $\gamma$ or TNF- $\alpha$ produced by MAIT cells in IBD patients (online suppl. Fig. 5). However, there was no correlation between PD-1 expression and IL-17 production. The analysis also showed no correlation between chemokine receptor expression and cytokine production. PD-1, a well-known coinhibitory molecule expressed on $\mathrm{T}$ cells, has been implicated in the exhaustion and anergy of T cells $[49,50]$. Collectively, these findings suggest that impaired production of proinflammatory cytokines by MAIT cells in IBD patients may be associated with MAIT cell anergy or exhaustion.

In the present study, IFN- $\gamma$ production by MAIT cells was found to be mainly regulated by the $\mathrm{Ca}^{2+} /$ calcineurin/NFAT1 signaling pathway. Our Western blot analysis showed that circulating MAIT cells displayed reduced activation of NFAT1 transcription factor in IBD patients, indicating that reduced IFN- $\gamma$ production by MAIT cells was due to defective NFAT1 activation. This is consistent with our previous study showing defective NFAT1-dependent IFN- $\gamma$ production by MAIT cells in systemic lupus erythematosus [20]. Teixeira et al. [51] have also shown that IFN- $\gamma$ production by $\mathrm{CD} 8+\mathrm{T}$ cells depends on NFAT1 transcription factor. Further analysis is needed to determine what factors can cause defective NFAT1 activation in MAIT cells.

\section{Conclusions}

This study shows that circulating MAIT cells are numerically and functionally deficient in IBD patients and that the reduced number of MAIT cells may be associated with disease activity. In addition, we report that MAIT cells are activated and have the potential to migrate into inflamed intestinal tissues. Increased ratio of IL-17/IFN- $\gamma$ production by MAIT cells is likely to be associated with defective activation of NFAT1, a critical transcription factor for IFN- $\gamma$ production in IBD patients. These results suggest that cytokine secretion profile in MAIT cells may contribute to regulation of mucosal immunity in IBD.

J Innate Immun 2020;12:422-433

DOI: $10.1159 / 000507931$ 


\section{Acknowledgements}

This study was supported by grants from the National Research Foundation of Korea funded by the Korean government (2019R1A2C1003238, 2018R1A6A3A11042850, and 2017R1D1A1B03034128), Chonnam National University Hospital Biomedical Research Institute (CRI17034-22), and Chonnam University Research Institute of Medical Sciences (2015-CURIMS-DR008).

\section{Statement of Ethics}

The study protocol was approved by the Institutional Review Board of Chonnam National University Hospital (CNUH-2017053). Written informed consent was obtained from all participants in accordance with the Declaration of Helsinki.

\section{Disclosure Statement}

The authors declare that they have no competing interests.

\section{Author Contributions}

J.K.J., Y.-N.C., K.-J.P., H.D.K., H.-M.J., S.-Y.P., H.S.K., S.-J.K., and Y.-W.P. designed this study, collected clinical information, analyzed raw data, performed statistical analysis, and contributed to writing of the paper. J.K.J., Y.-N.C., K.-J.P., and H.-M.J. performed experiments. All authors read and approved the final version of the manuscript.

\section{References}

1 Xavier RJ, Podolsky DK. Unravelling the pathogenesis of inflammatory bowel disease. Nature. 2007 Jul 26;448(7152):427-34.

2 Garrett WS, Gordon JI, Glimcher LH. Homeostasis and inflammation in the intestine. Cell. 2010 Mar 19;140(6):859-70.

3 Fonseca-Camarillo G, Yamamoto-Furusho JK. Immunoregulatory pathways involved in inflammatory bowel disease. Inflamm Bowel Dis. 2015 Sep;21(9):2188-93.

4 Zhang YZ, Li YY. Inflammatory bowel disease: pathogenesis. World J Gastroenterol. 2014 Jan 7;20(1):91-9.

5 Giuffrida P, Corazza GR, Di Sabatino A. Old and new lymphocyte players in inflammatory bowel disease. Dig Dis Sci. 2018 Feb;63(2): 277-88.

6 Geremia A, Biancheri P, Allan P, Corazza GR, Di Sabatino A. Innate and adaptive immunity in inflammatory bowel disease. Autoimmun Rev. 2014 Jan;13(1):3-10.

7 Treiner E, Duban L, Bahram S, Radosavljevic M, Wanner V, Tilloy F, et al. Selection of evolutionarily conserved mucosal-associated invariant T cells by MR1. Nature. 2003 Mar 13; 422(6928):164-9.

8 Kjer-Nielsen L, Patel O, Corbett AJ, Le Nours J, Meehan B, Liu L, et al. MR1 presents microbial vitamin B metabolites to MAIT cells. Nature. 2012 Nov 29;491(7426):717-23.

9 Napier RJ, Adams EJ, Gold MC, Lewinsohn DM. The role of mucosal associated invariant $\mathrm{T}$ cells in antimicrobial immunity. Front Immunol. 2015;6:344.

10 Le Bourhis L, Martin E, Péguillet I, Guihot A, Froux N, Coré M, et al. Antimicrobial activity of mucosal-associated invariant $\mathrm{T}$ cells. Nat Immunol. 2010 Aug;11(8):701-8.

11 Dusseaux M, Martin E, Serriari N, Péguillet I, Premel V, Louis D, et al. Human MAIT cells are xenobiotic-resistant, tissue-targeted, CD161hi IL-17-secreting T cells. Blood. 2011 Jan 27;117(4):1250-9.
12 Cosgrove C, Ussher JE, Rauch A, Gärtner K, Kurioka A, Hühn MH, et al. Early and nonreversible decrease of CD161++/MAIT cells in HIV infection. Blood. 2013 Feb 7;121(6):95161.

13 Leeansyah E, Ganesh A, Quigley MF, Sönnerborg A, Andersson J, Hunt PW, et al. Activation, exhaustion, and persistent decline of the antimicrobial MR1-restricted MAIT-cell population in chronic HIV-1 infection. Blood. 2013 Feb 14;121(7):1124-35.

14 Meierovics A, Yankelevich WJ, Cowley SC. MAIT cells are critical for optimal mucosal immune responses during in vivo pulmonary bacterial infection. Proc Natl Acad Sci U S A. 2013 Aug 13;110(33):E3119-28.

15 Grimaldi D, Le Bourhis L, Sauneuf B, Dechartres A, Rousseau C, Ouaaz F, et al. Specific MAIT cell behaviour among innate-like $\mathrm{T}$ lymphocytes in critically ill patients with severe infections. Intensive Care Med. 2014 Feb; 40(2):192-201.

16 Jiang J, Wang X, An H, Yang B, Cao Z, Liu Y, et al. Mucosal-associated invariant T-cell function is modulated by programmed death-1 signaling in patients with active tuberculosis. Am J Respir Crit Care Med. 2014 Aug 1;190(3):329-39.

17 Kim JC, Jin HM, Cho YN, Kwon YS, Kee SJ, Park YW. Deficiencies of circulating mucosalassociated invariant $\mathrm{T}$ cells and natural killer $\mathrm{T}$ cells in patients with acute cholecystitis. J Korean Med Sci. 2015 May;30(5):606-11.

18 Kwon YS, Cho YN, Kim MJ, Jin HM, Jung HJ, Kang JH, et al. Mucosal-associated invariant $\mathrm{T}$ cells are numerically and functionally deficient in patients with mycobacterial infection and reflect disease activity. Tuberculosis. 2015 May;95(3):267-74.

19 Miyazaki Y, Miyake S, Chiba A, Lantz O, Yamamura T. Mucosal-associated invariant T cells regulate Th1 response in multiple sclerosis. Int Immunol. 2011 Sep;23(9):529-35.
20 Cho YN, Kee SJ, Kim TJ, Jin HM, Kim MJ, Jung HJ, et al. Mucosal-associated invariant T cell deficiency in systemic lupus erythematosus. J Immunol. 2014 Oct 15;193(8):3891901.

21 Serriari NE, Eoche M, Lamotte L, Lion J, Fumery M, Marcelo P, et al. Innate mucosalassociated invariant T (MAIT) cells are activated in inflammatory bowel diseases. Clin Exp Immunol. 2014 May;176(2):266-74.

22 Ruijing X, Mengjun W, Xiaoling Z, Shu P, Mei $\mathrm{W}$, Yingcheng Z, et al. Ja33+ MAIT cells play a protective role in TNBS induced intestinal inflammation. Hepatogastroenterology. 2012 May;59(115):762-7.

23 Hiejima E, Kawai T, Nakase H, Tsuruyama T, Morimoto T, Yasumi T, et al. Reduced numbers and proapoptotic features of mucosalassociated invariant $\mathrm{T}$ cells as a characteristic finding in patients with inflammatory bowel disease. Inflamm Bowel Dis. 2015 Jul;21(7): 1529-40.

24 Tominaga K, Yamagiwa S, Setsu T, Kimura N, Honda $\mathrm{H}$, Kamimura $\mathrm{H}$, et al. Possible involvement of mucosal-associated invariant $\mathrm{T}$ cells in the progression of inflammatory bowel diseases. Biomed Res. 2017;38(2):111-21.

25 Walsh AJ, Ghosh A, Brain AO, Buchel O, Burger D, Thomas S, et al. Comparing disease activity indices in ulcerative colitis. J Crohns Colitis. 2014 Apr;8(4):318-25.

26 Feagan BG, Sandborn WJ, D’Haens G, Panés J, Kaser A, Ferrante M, et al. Induction therapy with the selective interleukin-23 inhibitor risankizumab in patients with moderate-tosevere Crohn's disease: a randomised, double-blind, placebo-controlled phase 2 study. Lancet. 2017 Apr 29;389(10080):1699-709.

27 Gajendran M, Loganathan P, Catinella AP, Hashash JG. A comprehensive review and update on Crohn's disease. Dis Mon. 2018 Feb; 64:20-57. 
28 Martin E, Treiner E, Duban L, Guerri L, Laude H, Toly C, et al. Stepwise development of MAIT cells in mouse and human. PLoS Biol. 2009 Mar 10;7(3):e54.

29 Sada-Ovalle I, Chiba A, Gonzales A, Brenner $\mathrm{MB}$, Behar SM. Innate invariant NKT cells recognize Mycobacterium tuberculosis-infected macrophages, produce interferongamma, and kill intracellular bacteria. PLoS Pathog. 2008 Dec;4(12):e1000239.

30 Humar M, Pischke SE, Loop T, Hoetzel A, Schmidt R, Klaas C, et al. Barbiturates directly inhibit the calmodulin/calcineurin complex: a novel mechanism of inhibition of nuclear factor of activated T cells. Mol Pharmacol. 2004 Feb;65(2):350-61.

31 Jin HM, Kee SJ, Cho YN, Kang JH, Kim MJ, Jung HJ, et al. Dysregulated osteoclastogenesis is related to natural killer T cell dysfunction in rheumatoid arthritis. Arthritis Rheumatol. 2015 Oct;67(10):2639-50.

32 Tsushima F, Yao S, Shin T, Flies A, Flies S, Xu $\mathrm{H}$, et al. Interaction between $\mathrm{B} 7-\mathrm{H} 1$ and $\mathrm{PD}-1$ determines initiation and reversal of T-cell anergy. Blood. 2007 Jul 01;110(1):180-5.

33 Chikuma S, Terawaki S, Hayashi T, Nabeshima R, Yoshida T, Shibayama S, et al. PD1-mediated suppression of IL-2 production induces CD8+ T cell anergy in vivo. J Immunol. 2009 Jun 01;182(11):6682-9.

34 Haga K, Chiba A, Shibuya T, Osada T, Ishikawa $\mathrm{D}$, Kodani T, et al. MAIT cells are activated and accumulated in the inflamed mucosa of ulcerative colitis. J Gastroenterol Hepatol. 2016 May;31(5):965-72.

35 Eberhard JM, Hartjen P, Kummer S, Schmidt RE, Bockhorn M, Lehmann C, et al. CD161+ MAIT cells are severely reduced in peripheral blood and lymph nodes of HIV-infected individuals independently of disease progression. PLoS One. 2014;9(11):e111323.
36 Willing A, Leach OA, Ufer F, Attfield KE, Steinbach K, Kursawe N, et al. CD8 ${ }^{+}$MAIT cells infiltrate into the CNS and alterations in their blood frequencies correlate with IL-18 serum levels in multiple sclerosis. Eur J Immunol. 2014 Oct;44(10):3119-28.

37 Magalhaes I, Pingris K, Poitou C, Bessoles S, Venteclef N, Kiaf B, et al. Mucosal-associated invariant $\mathrm{T}$ cell alterations in obese and type 2 diabetic patients. J Clin Invest. 2015 Apr; 125(4):1752-62.

38 Apostolopoulos V, de Courten MP, Stojanovska L, Blatch GL, Tangalakis K, de Courten $\mathrm{B}$. The complex immunological and inflammatory network of adipose tissue in obesity. Mol Nutr Food Res.2016 Jan;60(1):43-57.

39 Kang SJ, Jin HM, Won EJ, Cho YN, Jung HJ, Kwon YS, et al. Activation, impaired tumor necrosis factor- $a$ production, and deficiency of circulating mucosal-associated invariant $\mathrm{T}$ cells in patients with scrub typhus. PLoS Negl Trop Dis. 2016 Jul;10(7):e0004832.

40 Kwon YS, Jin HM, Cho YN, Kim MJ, Kang $\mathrm{JH}$, Jung HJ, et al. Mucosal-associated invariant $\mathrm{T}$ cell deficiency in chronic obstructive pulmonary disease. COPD. 2016;13(2):196202.

41 Won EJ, Ju JK, Cho YN, Jin HM, Park KJ, Kim $\mathrm{TJ}$, et al. Clinical relevance of circulating mucosal-associated invariant $\mathrm{T}$ cell levels and their anti-cancer activity in patients with mucosal-associated cancer. Oncotarget. 2016 Nov 15;7(46):76274-90.

42 Rouxel O, Da Silva J, Beaudoin L, Nel I, Tard C, Cagninacci L, et al. Cytotoxic and regulatory roles of mucosal-associated invariant $\mathrm{T}$ cells in type 1 diabetes. Nat Immunol. 2017 Dec;18(12):1321-31.

43 Touch S, Assmann KE, Aron-Wisnewsky J, Marquet F, Rouault C, Fradet M, et al. Mucosal-associated invariant T (MAIT) cells are depleted and prone to apoptosis in cardiometabolic disorders. FASEB J. 2018 Sep;32(9): 5078-89.
44 Jo YG, Choi HJ, Kim JC, Cho YN, Kang JH, Jin HM, et al. Deficiencies of circulating mucosal-associated invariant $\mathrm{T}$ cells and natural killer T cells in patients with multiple trauma. J Korean Med Sci. 2017 May;32(5):750-6.

45 Sandborn WJ, Feagan BG, Fedorak RN, Scherl E, Fleisher MR, Katz S, et al. A randomized trial of ustekinumab, a human interleukin-12/23 monoclonal antibody, in patients with moderate-to-severe Crohn's disease. Gastroenterology. 2008 Oct;135(4):1130-41.

46 Ogawa A, Andoh A, Araki Y, Bamba T, Fujiyama Y. Neutralization of interleukin-17 aggravates dextran sulfate sodium-induced colitis in mice. Clin Immunol. 2004 Jan;110(1): 55-62.

47 Hueber W, Sands BE, Lewitzky S, Vandemeulebroecke M, Reinisch W, Higgins PD, et al. Secukinumab, a human anti-IL-17A monoclonal antibody, for moderate to severe Crohn's disease: unexpected results of a randomised, double-blind placebo-controlled trial. Gut. 2012 Dec;61(12):1693-700.

48 Trivedi PJ, Adams DH. Chemokines and chemokine receptors as therapeutic targets in inflammatory bowel disease; pitfalls and promise. J Crohns Colitis. 2018 Aug 22;12(Suppl 2):S641-S52.

49 Keir ME, Butte MJ, Freeman GJ, Sharpe AH. $\mathrm{PD}-1$ and its ligands in tolerance and immunity. Annu Rev Immunol. 2008;26:677-704.

50 Wherry EJ. Immunology: T-cell exhaustion limits immune reactivity and is associated with good prognosis in autoimmune disease. Nat Rev Rheumatol. 2011 Jun;11(9):501-9.

51 Teixeira LK, Fonseca BP, Vieira-de-Abreu A, Barboza BA, Robbs BK, Bozza PT, et al. IFNgamma production by $\mathrm{CD} 8+\mathrm{T}$ cells depends on NFAT1 transcription factor and regulates Th differentiation. J Immunol. 2005 Nov 1; 175(9):5931-9. 